\title{
BMJ Health \& Care Informatics \\ Improving the evidence base for digital health interventions to increase contraception use
}

\author{
Chris Smith (10) ${ }^{1,2}$
}

To cite: Smith C. Improving the evidence base for digital health interventions to increase contraception use. BMJ Health Care Inform 2021;28:e100346. doi:10.1136/ bmjhci-2021-100346

Accepted 29 March 2021
Contraception is a lifesaving and essential component of healthcare. Since COVID-19 disrupted routine health service delivery, increased use of digital health (or mHealth) has been required to reduce risks to patients and healthcare workers ${ }^{12} \mathrm{~A}$ recent systematic review was, however, unable to draw concrete conclusions on the overall effectiveness of mHealth interventions to increase contraception use in low-income and middle-income countries. ${ }^{3}$ A meta-analysis was not possible due to differences between study populations, interventions and outcomes. In the meantime, another trial reported no measurable effect of an mHealth intervention for female sex workers on unintended pregnancy in Kenya, adding to the mixed evidence. ${ }^{4} \mathrm{~A}$ better evidence base for digital health interventions to increase contraception use is required, but how can this be achieved?

First, a common set of study outcome measures for interventions for contraception is required. To date, a variety of approaches to measuring contraception use have been used, to assess current use or adherence over time. While objective measures such as using biological markers or electronic medication monitors are considered less prone to bias, their use is challenging. ${ }^{5}$ Thus subjective measures enquiring about self-reported use remain de rigueur for most trials, accepting their known biases. An expert working group could be convened with the aim of harmonising contraceptive trial outcomes in order to reduce heterogeneity between studies and allow future meta-analyses.

Second, a deeper examination of the intervention mode of delivery and resource requirements is required. Distinctions between unidirectional and interactive interventions are important but the intensity and mode of interaction needs further evaluation. The ideal digital health intervention would be fully automated, scalable, safe and effective. It remains to be seen whether this is possible for contraception where there are a wide range of methods, cultural beliefs and nuanced side effects. Further understanding of the degree of personal interaction required and overall resource implications are important considerations for service providers when considering replicability and scale.

Third, now is the time to conduct larger studies that have shown to be effective, or promising but underpowered, and prioritised over trials of new interventions. Trials could be undertaken in different settings, but use the same outcome measures, maintaining the core components of the original intervention, subject to cultural or linguistic adaptions that might be required. This should result in an increased evidence base for service providers wanting to adopt best practices in digital health in their contraception programmes.

Funding The author has not declared a specific grant for this research from any funding agency in the public, commercial or not-for-profit sectors.

Competing interests None declared.

Patient consent for publication Not required.

Provenance and peer review Not commissioned; internally peer reviewed.

Open access This is an open access article distributed in accordance with the Creative Commons Attribution Non Commercial (CC BY-NC 4.0) license, which permits others to distribute, remix, adapt, build upon this work non-commercially, and license their derivative works on different terms, provided the original work is properly cited, appropriate credit is given, any changes made indicated, and the use is non-commercial. See: http://creativecommons.org/licenses/by-nc/4.0/.

ORCID iD

Chris Smith http://orcid.org/0000-0001-9238-3202

\section{REFERENCES}

1 Nanda K, Lebetkin E, Steiner MJ, et al. Contraception in the era of COVID-19. Glob Heal Sci Pract 2020;8:166-8.

2 Peek N, Sujan M, Scott P. Digital health and care in pandemic times: impact of COVID-19. BMJ Health Care Inform 2020;27:e100166. 
3 Aung B, Mitchell JW, Braun KL. Effectiveness of mHealth interventions for improving contraceptive use in low- and middleincome countries: a systematic review. Glob Heal Sci Pract 2020;8:813-26.

4 Ampt FH, Lim MSC, Agius PA, et al. Effect of a mobile phone intervention for female sex workers on unintended pregnancy in Kenya
(WHISPER or SHOUT): a cluster-randomised controlled trial. The Lancet Glob Heal 2020;8:e1534-45.

5 Smith C, Edwards P, Free C. Assessing the validity and reliability of self- report data on contraception use in the mobile technology for improved family planning (motif) randomised controlled trial. Trials 2018:1-5. 